\title{
Analisis Semiotika Makna Optimisme pada Video Klip Super-M “We-Do"
}

\author{
Kimberly Surjanto ${ }^{1}$, Gregorius Genep Sukendro ${ }^{2 *}$ \\ ${ }^{1}$ Fakultas Ilmu Komunikasi, Universitas Tarumanagara, Jakarta \\ Email: Kimberly.915180095@stu.untar.ac.id \\ ${ }^{2}$ Fakultas Ilmu Komunikasi, Universitas Tarumanagara, Jakarta* \\ Email: Geneps@fikom.untar.ac.id
}

Masuk tanggal : 15-12-2021, revisi tanggal : 06-01-2022, diterima untuk diterbitkan tanggal : 06-01-2022

\begin{abstract}
Video clips are communication media that have meaning. To reveal a meaning, it is necessary to analyze using semiotic method. There are various types of semiotic methods, one of which is John Fiske's semiotic method. Using this method, the researcher wants to know the meaning of optimism described in the Super-M video clip with the title "We-Do". This video clip was released during a pandemic with the aim of improving the quality of life both physically and psychologically. Video clips of published works of art are able to convey a message to the audience. Psychologically, works of art can have an emotional impact and can even change a person's mindset. The pandemic conditions are not easy, resulting in various problems, one of which is mental health problems. By using semiotic analysis, it is expected to find pictures of the meaning of optimism in the video clip. From the results of this study, found several signs that indicate the meaning of optimism. The meaning of optimism contained in the video clip "We-Do" leads to positive thinking and moving forward to face all challenges. Passion in facing everything and focus on one goal to move forward.
\end{abstract}

Keywords: John Fiske, optimism, semiotics, video clip

\begin{abstract}
Abstrak
Video klip merupakan media komunikasi yang memiliki makna. Untuk menguak suatu makna maka dibutuhkan analisis menggunakan metode semiotika. Metode semiotika sendiri memiliki berbagai jenis, salah satunya adalah metode semiotika John Fiske. Menggunakan metode ini, peneliti ingin mengtahui makna optimisme yang digambarkan dalam video klip Super-M dengan judul "We-Do". Video klip ini dirilis pada kondisi pandemi dengan tujuan untuk meningkatkan kualitas hidup baik secara fisik maupun psikis.Video klip hasil karya seni yang dipublikasikan mampu membawa pesan bagi kahalyak. Secara psikologis, karya seni mampu memberikan dampak secara emosional bahkan dapat mengubah pola pikir seseorang. Kondisi pandemi yang tidak mudah, mengakibatkan berbagai masalah, salah satunya adalah masalah kesehatan mental. Dengan menggunakan analisis semiotika, diharapkan dapat menemukan gambaran-gambaran makna optimisme pada video klip tersebut. Dari hasil penelitian ini, ditemukan beberapa tanda yang menunjukkan makna optimisme. Makna optimisme yang terkandung dalam video klip "We-Do" mengarah pada berpikir positif dan terus maju menghadapi segala tantagan. Semangat dalam menghadapi segala hal dan fokus pada satu tujuan untuk maju.
\end{abstract}

Kata Kunci: John Fiske, optimisme, semiotika, video klip 


\section{Pendahuluan}

Pandemi Covid-19 membawa dampak pada sektor ekonomi, sosial dan kesehatan. Salah satu hal yang menjadi perhatian dalam aspek kesehatan tidak hanya masalah kesehatan secara fisik, namun juga kesehatan psikis atau mental. Organisasi Kesehatan Dunia atau World Health Organization (WHO) telah mencatat adanya peningkatan layanan kesehatan mental dalam kurun waktu kurang dari 6 bulan pada paruh kedua 2020 (Fadli, 2020). Tidak semua individu memiliki kekuatan mental yang sama untuk menghadapi kondisi yang sulit. Dalam kehidupan, salah satu penggerak kehidupan adalah semangat. Semangat yang berasal dari dalam diri seseorang dan erat kaitannya dengan emosi dan psikologi.

Sebagai salah satu bentuk kontribusi kepada masyarakat, salah satu boyband asal Korea Selatan yakni Super-M berkolaborasi bersama dengan Prudential Asia merilis sebuah karya dalam bentuk video dan lagu. Video klip yang berjudul "We-Do" berdurasi 3 menit dan 58 detik telah dirilis secara resmi oleh SM Entertainment pada 9 April 2021. Melalui press release Super-M dan Prudential Asia (Prudential Indonesia, 2021), diharapkan melalui video klip ini dapat menyebarkan energi positif dan semangat hidup. Kesehatan bukan hanya secara fisik namun juga secara psikis.

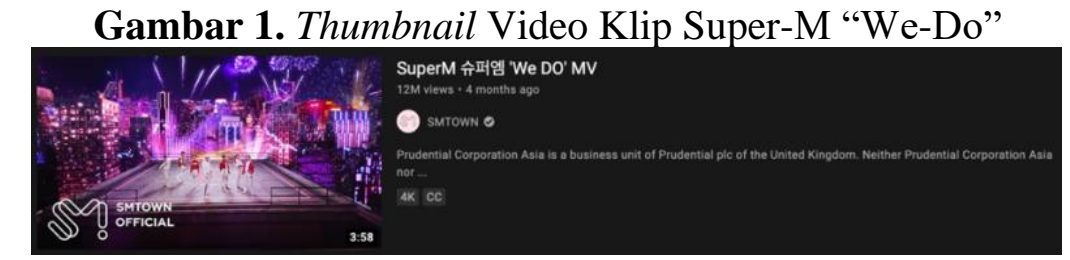

Sumber: Dokumentasi Pribadi

Super-M yang digadang-gadang sebagai avengers of KPOP turun andil dalam berbagai kampanye secara global (Benjamin, 2019). Salah satunya adalah "Global Citizen Recovery Plan for The World". Terlebih saat ini boyband asal Korea Selatan sedang mendapat banyak perhatian dari masyarakat dunia. SM Entertainment selaku agensi yang menaungi Super-M, membentuk Super-M untuk pasar internasional. Sehingga, dengan andil Super-M secara global diharapkan membawa dampak yang besar bagi masyarakat.

Melalui penelitian ini, peneliti memiliki sebuah rumusan masalah yakni; Bagaimana optimisme tergambarkan dalam video klip tersebut? Dengan tujuan penelitian untuk mengetahui makna optimisme yang tergambarkan dalam video klip Super-M "We-Do". Dengan demikian, untuk menguak sebuah makna dibutuhkan analisa semiotika. Semiotika sendiri merupakan ilmu yang mempelajari tanda yang ada di dalam masyarakat.

Semiotika dalam ranah komunikasi menurut (Mudjiyanto et al., 2013) membahas mengenai produksi suatu tanda yang terbentuk atas 6 faktor dalam komunikasi. Ke-enam faktor komunikasi tersebut adalah sender, receiver, meesage, communication dan target communication. Tanda adalah stimulus dari pesan yang disampaikan oleh sender dan selaras dengan receiver. Kemudian tanda-tanda tersebut dimaknai oleh receiver sehingga tanda tersebut berharga dan berarti.

Dalam semiotika, terdapat beberapa tokoh yang terkenal seperti Saussure, Pierce dan Roland Barthes. Namun perkembangan dalam ilmu semiotika terus berkembang. Salah satunya adalah model semiotika John Fiske. Fiske berangkat dari dunia televisi dan film. Sehingga model semiotika Fiske banyak mengacuh pada tanda- 
tanda yang dikemas secara visual. Dalam buku Television Culture, Fiske memaparkan mengenai The Television Codes, bahwa dalam semiotika terdapat tiga level yakni Level Realitas, Level Representasi dan Level Ideologi. Pengambilan gambar secara teknis menyimpan makna (Rini \& Fauziah, 2019).

Sementara itu, video klip merupakan salah satu hasil dari dunia film/televisi. Video klip dapat menjadi sebuah alat komunikasi massa, mengingat saat ini merupakan era digitalisasi. Menurut (Fiske, 2012) dalam buku Pengantar Ilmu Komunikasi, komunikasi massa merupakan proses sebuah pesan dikirim melalui media. Video klip merupakan media dari pesan tersebut. Sehingga video klip dapat dikategorikan sebagai alat komunikasi.

McQuail dalam (Prasetya, 2019) menyatakan bahwa ideologi dalam sebuah film mampu mengkonstruksi sebuah pola pikir yang berdampak pada kehidupan masyarakat. Hal ini berarti pesan-pesan yang terkandung di dalam sebuah film maupun video mampu mengubah pola pikir khalayaknya. Pengaruh emosi yang dibentuk oleh film jauh lebih besar dibandingkan dengan media massa lainnya (Salim \& Sukendro, 2021). Betapa hebatnya dampak dari pesan yang terkandung dalam video maupun film. Visualisasi dalam video klip sangat penting untuk mendukung hal tersebut. Dalam pengambilan gambar untuk video, beberapa aspek yang diperhatikan antara lain shot/angle, pencahayaan, tata rias, kostum, background music.

Pun manusia terdiri atas jiwa dan raga, semangat untuk menjalani kehidupan merupakan salah satu alasan untuk manusia terus berjuang. Semangat hidup sendiri berikaitan dengan optimisme dan konsep diri. Optimisme menurut para ahli psikologi dalam (A \& Dr. Hamdani M. Syam, 2017) adalah bentuk dari penyandagunaan diri yakni suatu keyakinan bahwa manusia mampu menguasai setiap hal yang dialami. Martin Seligman, seorang ahli psikologi mengatakan bahwa dengan adanya optimisme dalam kehidupan, maka seseorang lebih cepat keluar dari keputusasaan dan keterpurukkan (Thanoesya et al., 2016). Terdapat tiga dimensi dalam konsep diri yang dipaparkan oleh Seligman dalam (Pratisti \& Helmi, 2014) yakni permanence, persasivenes dan personalization.

Permanence adalah sebuah pandangan bahwa kegagalan bukan hal yang negatif dan dapat diperbaiki di masa depan. Kegagalan adalah sesuatu yang dapat dikendalikan oleh manusia. Persasiveness merupakan pandangan bahwa dalam kondisi seburuk apapun, terdapat sisi positif yang dapat diambil. Untuk personalization adalah pandangan bahwa hal negatif berasal dari eksternal dan hal positif berasal dari internal individu.

Dari paparan di atas, maka dihasilkan sebuah kerangka pemikiran sebagai berikut:

Bagan 1. Kerangka Pemikiran

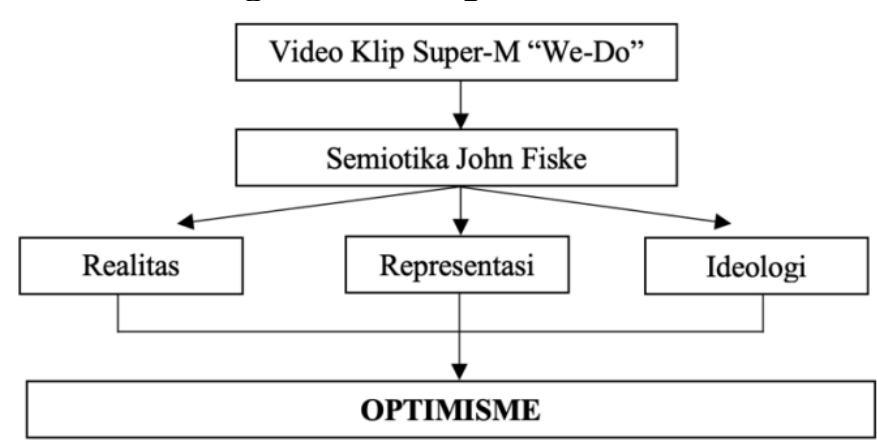

Sumber: Dokumentasi Pribadi 


\section{Metode Penelitian}

Penelitian ini menggunakan pendekatan kualitatif deskriptif. Penelitian kualitatif bertujuan untuk mengetahui sebuah peristiwa dan tidak berkaitan dengan statistik. Sebuah penelitian kualitatif merupakan penelitian yang bersifat value bound (Rukajat, 2018). Peneliti diposisikan sebagai instrumen yang sangat penting. Sehingga kesimpulan dari penelitian kualitatif umumnya bersifat subyektif. Data-data didapatkan dengan interaksi antar peneliti dan subyek penelitian. Beberapa alasan dipilih penelitian kualitatif untuk penelitian ini karena tujuan dari penelitian ini adalah untuk mengdeskripsikan makna optimisme yang terkandung dalam sebuah video klip.

Metode dari penelitian yang digunakan adalah analisis semiotika. Analisis semiotika menitikberatkan pada tanda-tanda di dalam masyarakat dan pemaknaannya. Semiotika sendiri adalah cabang ilmu yang memperdalam mengenai kajian tanda. Beberapa ahli semiotika yang terkenal seperti Saussure, Pierce, Roland Barthes dan John Fiske memiliki cara analisis dan pandangan yang berbeda mengenai semiotika. Saussure dengan analisis penanda-petanda, Pierce dengan Triadic Model, Roland Barthes dengan konotasi-denotasi-mitos, kemudian John Fiske dengan level realitaslevel representasi-level ideologi.

Penelitian ini menggunakan analisis semiotika John Fiske dikarenakan beberapa alasan. John Fiske berangkat dari dunia televisi dan film sehingga akan lebih cocok digunakan untuk mengkaji subjek yang merupakan hasil dari dunia televisi dan film yakni video klip. Bentuk dari subjek adalah audiovisual, dan dalam semiotika Fiske visual sangat diperhatikan baik dari pengambilan gambar hingga penyuntingan.

Subjek dari penelitian ini adalah video klip Super-M "We-Do" sedangkan untuk objek dari penelitian ini adalah makna optimisme. Subjek penelitian adalah sesuatu yang mampu memberikan informasi (Sugiyono, 2017). Sedangkan objek adalah masalah yang digali didalam sebuah penelitian (Patimah \& Murni, 2017).

Untuk mengumpulkan data-data yang diperlukan, peneliti menggunakan metode observasi, dokumentasi dan studi literatur. Observasi dilakuakn dengan mengamati subjek penelitian yakni video klip Super-M "We-Do" secara menyeluruh baik secara audio maupun visual. Kemudian untuk mempekuat data-data yang dimiliki, peneliti mendokumentasi adegan-adegan yang terdapat pada video klip tersebut. Studi literatur atau kepustakaan digunakan untuk mendukung penelitian. Terdapat dua sumber studi literatur yakni primer dan sekunder.

Dalam teknik pengolahan data, peneliti menggunakan teniknik analisis semiotika John Fiske yang dikenal juga sebagai The Television Codes.

Tabel 1. Analisis Semiotika John Fiske

\begin{tabular}{|l|l|}
\hline Level & Pembahasan \\
\hline REALITAS & $\begin{array}{l}\text { Peristiwa dalam film yang tergambarkan dan sudah memiliki } \\
\text { tanda dalam kehidupan sosial seperti tata rias, pakaian, } \\
\text { lingkungan, perilaku, gerak tubuh/ekspresi serta dialog. }\end{array}$ \\
\hline REPRESENTASI & $\begin{array}{l}\text { Kode-kode yang didukung secara teknis film seperti teknis } \\
\text { pengambilan gambar, pencahayaan, sunting, musik/suara. }\end{array}$ \\
\hline IDEOLOGI & $\begin{array}{l}\text { Kode-kode yang didapatkan dari level realitas dan representasi } \\
\text { kemudian disusun sedemikian rupa agar menghasilkan ideologi. } \\
\text { Ideologi secara sosial seperti patriarki, feminisme, ras, } \\
\text { kapitalisme, optimisme, dan lain-lain. Ideologi sendiri dapat } \\
\text { digali lebih dalam. }\end{array}$ \\
\hline
\end{tabular}

Sumber: (Hasanah \& Taefur, 2016) 
Kimberly Surjanto, Gregorius Genep Sukendro: Analisis Semiotika Makna Optimisme pada Video Klip Super-M "We-Do"

\section{Hasil Temuan dan Diskusi}

Video klip Super-M "We-Do" bedurasi 3 menit dan 58 detik dengan lagu yang upbeat. Pada keseluruhan video klip, kostum yang digunakan oleh seluruh anggota Super-M berwarna cerah. Selain itu warna yang mendominasi latar dari video adalah warna primer seperti merah dan kuning. Akan tetapi di bagian akhir video, warna yang mendominasi adalah warna merah, biru, ungu dan hitam. Warna merah terlihat hampir di setiap adegan. Warna merah menandakan semangat dan perjuangan, sedangkan warna kuning mengambarkan energi.

Selain warna yang mendominasi adegan, terdapat juga gestur yang sering terlihat dalam beberapa adegan, yakni gestur 'mengajak'. Beberapa anggota Super-M seperti Mark Lee, Kai dan Ten Lee menggunakan gestur tersebut pada beberapa bagian. Hal ini dapat diartikan bahwa Super-M mengajak khalayak untuk bersama-sama bergerak menuju kehidupan yang positif dan bangkit dari keterpurukkan.

Terdapat pula beberapa adegan di dalam lift yang sedang bergerak naik ke atas. Hal ini dapat menunjukkan adanya pergerakkan menuju suatu kondisi yang lebih baik, lebih positif. Seperti halnya dalam optimisme, individu bergerak maju menuju arah yang lebih baik. Hal-hal negatif atau kesalahan dapat diperbaiki di kemudian hari, maka manusia harus terus bergerak maju. Tidak terpaku pada suatu masalah dan menjadi ganjalan dan alasan untuk tidak bergerak maju.

Selain itu terdapat adegan, seseorang menekan tombol 'naik' pada lift. Menekan tombol lift adalah sebuah pilihan, pada lift terdapat dua buah tombol, yakni untuk naik dan turun. Namun yang dipilih adalah tombol naik. Hal ini menunjukkan bahwa dalam kehidupan terdapat pilihan, pilihan tersebut yang akan menentukan kehidupan akan di bawa kearah yang lebih baik atau lebih buruk. Dengan bergerak terus maju, maka rintangan bukanlah halangan. Individu yang memiliki optimis dalam hidupnya memiliki daya juang yang sangat besar. Tidak ada kata "putus asa" di dalam diri seorang yang optimis. Hal ini berkaitan dengan konsep optimisme Seligman yakni permanence. Seseorang mampu mengendalikan diri dalam berbagai kondisi. Walaupun menghadapi sebuah kegagalan, namun ada keinginan dan memiliki untuk terus maju.

Pada beberapa bagian di lirik lagu "We-Do" terdapat pesan-pesan yang menguatkan khalayak. "Cause we all came to run this. Didn't come this far for noting. We all here for just one thing. And now we boout' to life it up" dapat diterjemahkan menjadi "Karena kita semua datang untuk melakukan ini. Tidak datang sejauh ini untuk apa-apa. Kita semua di sini hanya untuk satu hal dan sekarang kita bertarung untuk menghidupkannya" dapat diartikan bahwa dalam kehidupan ada tujuan yang harus dicapai. Lirik tersebut mampu memberikan motivasi bagi khalayak yang mengalami demotivasi. Bahwa perjuangan yang telah dilakukan selama ini akan menjadi sia-sia apa tidak diteruskan. Segala usaha yang dilakukan sangat berarti dan aka nada waktunya untuk merasakan kesuksesan. Optimis akan hal yang akan datang di kemudian hari.

Kemudian "Get up, live your best life" yang dapat diterjemahkan menjadi "Bangun, jalani hidupmu sebaik-baiknya", melalui lirik ini khalayak diingatkan bahwa hidup yang hanya sekali harus dijalani sebaik-baiknya. Jangan sampai hidup menjadi sia-sia karena suatu masalah atau keputusasaan. Kondisi pandemi saat ini memang memukul masyarakat dari berbagai kalangan. Akan tetapi dengan adanya optimisme dalam hidup, maka kondisi bukanlah halangan. Seperti konsep personalization bahwa 
hal-hal negatif berasal dari eksternal dan masih ada berbagai kesempatan yang dapat dicapai.

Di akhir video, terdapat adegan seluruh anggota Super-M berada di helipad, umumnya helipad berada di puncak gedung pencakar langit. Pada adegan tersebut, ada beberapa efek seperti flare dan kembang api. Flare dapat memberikan makna bahwa anggota Super-M berbagi energi kepada khalayak. Energi untuk terus memiliki kehidupan yang lebih baik. Kembang api dapat di artikan sebagai sebuah kesuksesan akan sebuah pencapaian. Kembang api juga hanya terlihat pada saat seluruh anggota Super-M berada di puncak gedung pencakar langit. Puncak gedung pencakar langit melambangkan tujuan, yang artinya mereka sudah mencapai tujuan dan selebrasi akan pencapaian.

Di dalam hidup, rintangan yang dialami setiap individu berbeda-beda dan tujuan hidup pun berbeda-beda. Tidak mudah bagi manusia untuk selalu optimis setiap saat. Namun jangan biarkan masalah yang sedang dihadapi sebagai alasan untuk tidak bangkit. Super-M dalam video klip ini ingin memberikan semangat optimisme agar khalayak mampu bangkit dari masalah-masalah yang dialami. Tidak ada yang tidak mungkin dalam hidup ini.

\section{Simpulan}

Dari adegan-adegan yang ada pada video klip Super-M "We-Do" makna optimisme yang ingin disampaikan kepada khalayak adalah kondisi apapun yang sedang di hadapi dapat dilalui. Segala sesuatu dapat tercapai dengan adanya optimisme dan semangat. Super-M mengajak khalayak untuk kembali bangkit dan fokus pada tujuan hidup. Meninggalkan keputusasaan, karena kehidupa ini begitu berharga dan setiap orang memiliki kesempatan yang sama untuk merasakan keindahan dalam kehidupan.

Ajakan yang disampaikan oleh Super-M tidak lepas kaitannya dengan kondisi saat ini, dimana kondisi mental masyarakat sedang terguncang. Dikarenakan pandemi yang tidak kunjung reda dan berdampak dalam berbagai aspek kehidupan. Tidak sedikit masyarakat yang menjadi frustasi.

\section{Ucapan Terima Kasih}

Peneliti ingin mengucapkan terima kasih yang sebesar-besarnya kepada Fakultas Ilmu Komunikasi Universitas Tarumanagara, narasumber serta semua pihak yang turut membantu peneliti sehingga penelitian ini dapat diselesaikan.

\section{Daftar Pustaka}

A, M. R., \& Dr. Hamdani M. Syam, M. A. (2017). Analisis Semiotika Pesan-Pesan Optimisme dalam Film Sang Pemimpi. Jurnal Ilmiah Mahasiswa Fakultas Ilmu Sosial \& Ilmu Politik, 2(4), 287-298. http://www.jim.unsyiah.ac.id/FISIP/article/view/5552

Benjamin, J. (2019, August 7). SuperM, 'The Avengers Of K-Pop,' Unveiled By SM Entertainment And Capitol Music Group. https://www.forbes.com/sites/jeffbenjamin/2019/08/07/super-m-the-avengersof-k-pop-unveiled-by-sm-entertainment-and-capitol-musicgroup/?sh=217aeb546138 
Fadli, dr R. (2020, October 7). Survey WHO tentang Kesehatan Mental dan COVID19. https://www.halodoc.com/artikel/survey-who-tentang-kesehatan-mentaldan-covid-19

Fiske, J. (2012). Pengantar Ilmu Komunikasi (3rd ed.). Rajawali Pers.

Hasanah, R., \& Taefur, I. (2016). The Shift Meaning of Masculinity in Nivea Deodorant Men Invisible Black And White Advertising (Television code by John Fiske). International Conference on Transformation in Communication (ICOTIC), $O(0)$. https://openlibrarypublications.telkomuniversity.ac.id/index.php/icotic/article/ view/5657

Mudjiyanto, B., Nur, E., Pengkajian, B., Komunikasi, P., Jakarta, I., Pengkajian, B. B., Makassar, I., \& Abdurrahman Basalama, J. (2013). Semiotika Dalam Metode Penelitian Komunikasi Semiotics In Research Method of Communication. Informatika Dan Media Massa PEKOMMAS, 16(1).

Patimah, D., \& Murni. (2017). Analisis Kualitatif Gaya Berpikir Siswa SMA Dalam Memecahkan Masalah Fisika Pada Materi Gerak Parabola. Jurnal Inovasi dan Pembelajaran Fisika, 4(2), 106-118.

Prasetya, A. B. (2019). Analisis Semiotika Film dan Komunikasi.

Pratisti, W. D., \& Helmi, A. F. (2014). Dimensi Optimisme pada Remaja. http://publikasiilmiah.ums.ac.id/handle/11617/6408

Prudential Indonesia. (2021). Prudential Berkolaborasi dengan grup k-pop SuperM meluncurkan "We Do Well Together" | Prudential Indonesia. https://www.prudential.co.id/id/news/we-do-well-together/

Rini, K. P., \& Fauziah, N. (2019). Feminisme dalam Video Klip Blackpink: Analisis Semiotika John Fiske Dalam Video Klip Blackpink DDU-DU DDU-DU. Jurnal Komunikasi Universitas Garut: Hasil Pemikiran Dan Penelitian, 5(2), 317-328. https://doi.org/10.10358/JK.V5I2.669.G636

Rukajat, A. (2018). Pendekatan Penelitian Kualitatif. Deepublish.

Salim, V., \& Sukendro, G. G. (2021). Representasi Kritik Sosial dalam Film Parasite (Analisis Semiotika Roland Barthes). Koneksi, 5(2), 381-386. https://journal.untar.ac.id/index.php/koneksi/article/view/10387

Sugiyono. (2017). Metode Penelitian Kuantitatif, Kualitatif, dan R\&D (2nd ed.). Alfabeta.

Thanoesya, R., Syahniar, S., \& Ifdil, I. (2016). Konsep Diri dan Optimisme Mahasiswa dalam Proses Penulisan Skripsi. JPPI (Jurnal Penelitian Pendidikan Indonesia), 2(2), 58-61. https://doi.org/10.29210/02016183 